\title{
Levantamento soroepidemiológico para arbovírus em macaco-prego-galego (Cebus flavius) de vida livre no Estado da Paraíba e em macaco-prego (Cebus libidinosus) de cativeiro do Nordeste do Brasil ${ }^{1}$
}

\author{
Plautino 0. Laroque ${ }^{2,3 *}$, Mônica M. Valença-Montenegro ${ }^{3}$, Débora R.A. Ferreira ${ }^{2}$, \\ Jannifer O. Chiang ${ }^{4}$, Marli T. Cordeiro ${ }^{5}$, Pedro F.C. Vasconcelos ${ }^{4}$ e Jean C.R. Silva ${ }^{2,6,7}$
}

\begin{abstract}
Laroque P.O., Valença-Montenegro M.M., Ferreira D.R.A., Chiang J.O., Cordeiro M.T., Vasconcelos P.F.C. \& Silva J.C.R. 2014. [Epidemiologic survey for arbovirus in Galician capuchin monkeys (Cebus flavius) free living in Paraíba and captive capuchin monkey (Cebus libidinosus) from Northeast Brazil.] Levantamento soroepidemiológico para arbovírus em macaco-prego-galego (Cebus flavius) de vida livre no Estado da Paraíba e em macaco-prego (Cebus libidinosus) de cativeiro do Nordeste do Brasil. Pesquisa Veterinária Brasileira 34(5):462-468. Centro Nacional de Pesquisa e Conservação de Primatas Brasileiros, Instituto Chico Mendes de Conservação da Biodiversidade, Ministério do Meio Ambiente, Praça Antenor Navarro 5, Varadouro, João Pessoa, PB 58010-480, Brazil. E-mail: plautino@terra.com.br

This paper describes the first investigation of arbovirus antibodies on New World non-human primates from Northeast Brazil. From March 2008 to September 2010 blood serum samples were collected from 31 wild blond capuchin monkeys (Cebus flavius) from Paraíba and 100 captive capuchin monkeys from Alagoas, Paraíba, Pernambuco, Piauí and Rio Grande do Norte. The haemagglutination-inhibition test (HI) was employed for 19 arbovirus of the Flavivirus, Alphavirus and Bunyavirus genus. Serum samples were tested from 1:20 to 1:1280 dilutions. Among the primates tested all C. flavius were negative and $46 \%$ C. libidinosus presented antibodies to arbovirus. Antibodies were detected for nine arbovirus $(9 / 19)$. Seventeen heterotypic reactions were observed for at least two Or Flavirus and 15 for Alphavirus, at titers varying between 1:20 to 1:1280. Fifteen samples presented monotypic reaction for ILHV ( $n=4)$, MAYV $(n=6), \operatorname{SLEV~}(n=1), \operatorname{ROCV}(n=2), \operatorname{OROV}(n=1)$ and MUCV ( $n=1)$. These results suggest that there was an intense arbovirus circulation in the studied population of captive capuchin monkeys.
\end{abstract}

INDEX TERMS: Arbovirus, monkeys, Cebus flavius, Cebus libidinosus, non-human primates, arboviruses serology, Brazil.

RESUMO.- Este estudo descreve a primeira investigação de anticorpos para arbovírus em primatas não humanos do Novo Mundo no nordeste brasileiro. No período de março de 2008 a setembro de 2010 foram colhidos soros sanguí-

\footnotetext{
${ }^{1}$ Recebido em 24 de outubro de 2013.

Aceito para publicação em 18 de abril de 2014.

${ }^{2}$ Programa de Pós-Graduação em Ciência Veterinária, Universidade Federal Rural de Pernambuco (UFRPE), Rua Dom Manoel de Medeiros s/n, Dois Irmãos, Recife, PE 52171-900, Brasil. *Autor para correspondência: plautino@terra.com.br

${ }^{3}$ Centro Nacional de Pesquisa e Conservação de Primatas Brasileiros, Instituto Chico Mendes de Conservação da Biodiversidade, Ministério do Meio Ambiente, Praça Antenor Navarro 5, Varadouro, João Pessoa, PB 58010-480, Brasil.

${ }^{4}$ Seção de Arbovirologia e Febres Hemorrágicas, Instituto Evandro Cha-
}

neos de 31 macacos-prego-galegos (Cebus flavius) de vida livre na Paraíba e de 100 macacos-prego (Cebus libidinosus) em cativeiro nos estados de Alagoas, Paraíba, Pernambuco, Piauí e Rio Grande do Norte. Para a pesquisa de anticor-

gas, Secretaria de Vigilância em Saúde, Rodovia BR-316 Km 7, Ananindeua, PA 67030-300, Brasil.

${ }^{5}$ Centro de Pesquisa Aggeu Magalhães, Fiocruz, Avenida Professor Moraes Rego s/n, Cidade Universitária, Caixa Postal 7472, Recife, PE 50670420.

${ }^{6}$ Instituto Brasileiro para Medicina da Conservação, Tríade, Rua Silveira Lobo 32, Cx. Postal 48, Casa Forte, Recife, PE 52061-030.

7 Departamento de Medicina Veterinária Preventiva e Saúde Animal (VPS), Faculdade de Medicina Veterináriae Zootecnia, Universidade de São Paulo (USP), Av. Prof. Dr. Orlando Marques de Paiva 87, CidadeUniversitária, São Paulo, SP 05580-270, Brasil. 
pos utilizou-se o teste de inibição da hemaglutinação (IH), usando antígenos de 19 diferentes tipos de arbovírus, pertencentes aos gêneros Flavivirus, Alphavirus e Bunyavirus. As amostras de soro foram testadas nas diluições de 1:20 a 1:1280. Dentre as amostras examinadas, todas as de $C$. flavius foram negativas e $46 \%$ das de C. libidinosus em cativeiro apresentaram anticorpos para arbovírus. Foram detectados anticorpos para nove (9/19) arbovírus. Foram observadas 17 reações heterotípicas, para dois ou mais vírus, do gênero Flavivirus, e 15 para o gênero Alphavirus, com títulos variando de 1:20 a 1:1280. Quinze amostras apresentaram reação monotípica para ILHV ( $\mathrm{n}=4), \operatorname{MAYV}(\mathrm{n}=6), \operatorname{SLEV}(\mathrm{n}=1)$, ROCV (n=2), OROV ( $n=1)$ e MUCV $(n=1)$. Estes resultados sugerem que houve intensa circulação de arbovírus na população estudada de macacos-prego em cativeiro.

TERMOS DE INDEXAÇÃO: Arbovírus, macacos prego, Cebus flavius, Cebus libidinosus, Primatas não humanos, arboviroses, sorologia, Brasil.

\section{INTRODUÇÃO}

As mudanças ambientais naturais ou antrópicas desencadeiam modificações climáticas naturais cíclicas, ou por implantação de projetos para extrativismo dos recursos naturais, tais como desflorestamento, construção de barragens e rodovias, além da exploração de minério (Cruz \& Vasconcelos 2008). Aliado a estes fatores, as doenças infecciosas e parasitárias têm grande importância na saúde animal, na saúde pública e nas ações de vigilância ambiental.

Os animais silvestres são importantes reservatórios nos ciclos epidemiológicos das diversas zoonoses existentes, sendo os primatas não humanos (PNH) considerados animais "sentinelas naturais" para investigação de determinadas epizootias de interesse à saúde pública. Considerando o meio ambiente e suas condições propícias para a manutenção de diversos ciclos epidemiológicos, vários agentes etiológicos podem estar envolvidos em epizootias acometendo PNH, entre eles vírus, bactérias, protozoários, rickétsias, fungos e parasitas (Svoboda 2007).

Viroses têm sido estudadas em primatas e as investigações sorológicas realizadas indicam que as infecções virais nesses animais são comuns e frequentemente ocorrem como doenças não reconhecidas (Diniz 1997). A semelhança filogenética entre PNH e humanos permite a susceptibilidade a vários agentes etiológicos em comum, sendo que aproximadamente 150 enfermidades compartilhadas já foram reconhecidas e descritas (Fiennes et al. 1967). Diversos vírus foram descritos como agentes infecciosos frequentes associados às zoonoses, dentre eles os arbovírus (Dabanch 2003). Alguns arbovírus constituem sério problema de saúde pública, no âmbito regional ou globalmente, devido à expressiva morbidade e/ou mortalidade que ocasionam. Dentre eles o vírus da febre amarela (YFV), o vírus dengue (DENV), vírus Oropouche (OROV), vírus Mayaro (MAYV) e diversos agentes responsáveis por causar encefalites (Cruz \& Vasconcelos 2008).

As arboviroses, em sua quase totalidade, são zoonoses, ou seja, doenças ou infecções que acometem e são transmitidas aos animais vertebrados e ao homem, mantidas em ambiente silvestre. Consequentemente, as pessoas que mantêm contato com os focos enzoóticos dos arbovírus são as que correm maiores riscos de adquirirem a infecção. No entanto, certas arboviroses têm surgido periodicamente em áreas urbanas, de forma epidêmica, tais como febre do Oropouche, febre do Nilo Ocidental, febre do Mayaro e encefalite causada pelo vírus Rocio (Azevedo et al. 2007).

No Brasil, em virtude de sua magnífica biodiversidade e do estado delicado em que muitas espécies animais se encontram, é urgente o desenvolvimento de pesquisas, além do apoio às já existentes, que investiguem a ocorrência natural de patógenos e suas correspondentes enfermidades. Sem esse conhecimento, trabalhos conservacionistas importantes correm o risco de estarem destinados ao fracasso, seja pela morte de animais translocados e/ou reintroduzidos, seja pela possibilidade de induzirem desastres ecológicos, por meio da introdução de doenças em habitats originalmente isentos (Catão-Dias 2003).

Os primatas não humanos são reservatórios de uma grande variedade de agentes infecciosos com implicação para a saúde pública. Entretanto, apesar da legislação brasileira apenas permitir a criação em cativeiro doméstico de animais silvestres oriundos de criadouros comerciais legalizados, ainda é considerável o número de apreensões de PNH de origem ilegal em domicílios, o que reflete o desconhecimento da população sobre o risco de transmissão de zoonoses por estes animais (Pereira et al. 2010).

Diante do exposto, o presente estudo teve como objetivo investigar a presença de anticorpos contra os 19 arbovírus mais frequentes no Brasil, particularmente na Região Norte, em macacos-prego-galego (Cebus flavius) de vida livre no município de Santa Rita, estado da Paraíba e em macacos-prego (Cebus libidinosus) procedentes dos Centros de Triagens de Animais Silvestres (CETAS) / Instituto Brasileiro do Meio Ambiente e dos Recursos Naturais Renováveis (IBAMA) localizados no nordeste do Brasil.

\section{MATERIAL E MÉTODOS}

Esta investigação foi realizada em duas espécies de primatas que vêm sendo alvo de pesquisas do Centro Nacional de Pesquisa e Conservação de Primatas Brasileiros (CPB) do Instituto Chico Mendes de Conservação da Biodiversidade (ICMBio). No período de agosto de 2009 a setembro de 2010 foram colhidas amostras séricas de 31 macacos-prego-galego (Cebus flavius Schreber, 1774), de vida livre e clinicamente saudáveis. Os indivíduos foram capturados no fragmento de Mata Atlântica da Reserva Particular do Patrimônio Natural (RPPN) Engenho Gargaú, propriedade da Usina Japungu Agroindustrial S/A, no município de Santa Rita, localizado a $13,27 \mathrm{~km}$ de João Pessoa, Estado da Paraíba (0700' 3.84" S; 3455'24.96” W). Esta RPPN foi criada em 1994, por meio da Portaria IBAMA no64/1994-N e possui uma área de mata de $1.058,62$ ha, inserida numa matriz de canaviais.

No período de março de 2008 a outubro de 2010 foram colhidas amostras séricas de 100 macacos-prego (Cebus libidinosus Spix, 1823), clinicamente hígidos, sem distinção de sexo e idade, submetidos às condições de manejo clínico, nutricional e de saúde semelhantes, provenientes de cinco Centros de Triagem de Animais Silvestres (CETAS), pertencentes ao Instituto Brasileiro do Meio Ambiente e dos Recursos Naturais Renováveis (IBAMA). Dentre os 100 animais, cinco foram procedentes do CETAS de Maceió (AL) (09³6'53.60” S; 3544'28.32" W), 16 de Natal (RN) 


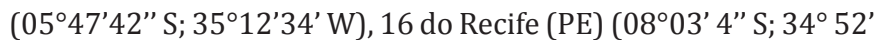
$52^{\prime \prime}$ W), 26 de Teresina (PI) $\left(05^{\circ} 05^{\prime} 21^{\prime \prime}\right.$ S; 42 $48^{\prime} 07^{\prime \prime}$ W) e 37 de Cabedelo (PB) $\left(07^{\circ} 06\right.$ 54" S; 3451 47" W). Com relação ao sexo, 56 eram machos e 44 fêmeas; com relação à idade, um era filhote, 19 eram juvenis e 80 eram adultos. Dentre os 31 indivíduos de macacos-prego-galego, com relação ao sexo, 19 eram machos e 12 eram fêmeas e com relação à idade, um era filhote, 10 eram juvenis e 20 eram adultos. Esta amostragem dos macacos-prego das duas espécies foi obtida de forma não probabilística e por conveniência (Reis 2003).

Em cativeiro a contenção dos macacos-prego foi realizada por meio físico, utilizando-se puçá e luva de raspa de couro, seguida de contenção química, utilizando-se cloridrato de cetamina na dose de $30 \mathrm{mg} / \mathrm{kg}$, administrado por via intramuscular após a adequada contenção física (Valença-Montenegro 2011). Para a contenção dos macacos-prego-galego de vida livre foram utilizadas 20 armadilhas live trap do tipo "Tomahawk", após habituação à ceva com utilização de milho, seguindo-se o mesmo protocolo, acima citado, de contenção química. 0 monitoramento dos animais foi realizado durante todo o procedimento anestésico.

Todos os componentes da equipe no momento do manejo estavam protegidos com os equipamentos de proteção individuais recomendados (luvas, máscara e roupa apropriada), evitando exposição a agentes zoonóticos.

Foram empregados no exame clínico, meios semiológicos descritos por Diniz (1997), como palpação abdominal e de linfonodos, avaliação clinica, por meio de inspeção física direta e indireta, aferição da temperatura, coloração das mucosas, auscultação cardíaca e pulmonar, bem como as características de pele e unhas. Além de aferição da massa corporal e demais etapas do manejo, como biometria, registro fotográfico e marcação por meio de tatuagem na face interna da coxa esquerda (Valença-Montenegro et al. 2009a, 2009b). Após a realização do exame e coleta da amostra de sangue, os primatas ficaram em observação até o retorno completo do plano anestésico. Em seguida, foram reconduzidos às respectivas condições de cativeiro ou vida livre.

A coleta de sangue foi realizada por punção da veia femoral em um volume inferior a $1 \%$ do peso de cada animal, na altura do trígono femoral na coxa. 0 sangue foi acondicionado em tubo à vácuo, tipo vacutainer com gel, em seguida deixado em repouso para formação e retração do coágulo e, logo depois, centrifugado. 0 soro obtido foi acondicionado em microtubos de polipropileno $(0,5 \mathrm{~mL})$, etiquetado com a identificação do animal e armazenado a $-20^{\circ} \mathrm{C}$, até a realização do teste sorológico.

A pesquisa de anticorpos para arbovírus no soro dos animais foi realizada por meio do teste de inibição da hemaglutinação (IH) utilizando-se a técnica descrita por Clarke e Casals (1958), adaptada por Shope (1963). Inicialmente, os soros $(50 \mu \mathrm{l})$ foram tratados com acetona para precipitação das imunoglobulinas, em seguida adsorvidos com uma suspensão de hemácias de ganso na proporção de 1:6, em salina borratada com $0,4 \%$ de albumina bovina, $\mathrm{pH}$ 9,0, para a remoção de inibidores inespecíficos, ficando o soro na diluição final de 1:20. Os antígenos utilizados foram preparados a partir da inoculação do vírus em cérebro de camundongos recém-nascidos, extraídos pelo método de sucrose-acetona (Beaty et al. 1986) e utilizados em uma diluição contendo quatro unidades hemaglutinantes, determinada por titulação prévia e de acordo com o pH e temperatura indicados para cada vírus. Os soros tratados (diluição de 1:20) foram inicialmente testados contra um painel de 19 arbovírus e as amostras com resultado positivo para algum tipo de vírus, foram diluídas a partir de 1:20 até 1:1280 e novamente submetidas ao teste IH para determinação do titulo de anticorpos para os arbovírus específicos. Os ensaios foram realizados no Laboratório de Arbovirologia e Febres Hemorrágicas do Instituto Evandro Chagas, Ananindeua, PA.
O painel de 19 tipos de arbovírus era constituído por: quatro Alphavirus da família Togaviridae - vírus da encefalite equina leste (EEEV), vírus da encefalite equina oeste (WEEV), vírus Mayaro (MAYV) e vírus Mucambo (MUCV); seis Flavivirus da família Flaviviridae - vírus da encefalite São Luís (SLEV), vírus Ilhéus (ILHV), vírus Rocio (ROCV), vírus da febre amarela (YFV), vírus Bussuquara (BSQV) e vírus Cacipacore (CPCV); oito Orthobunyavirus da família Bunyaviridae, vírus Oropouche (OROV), vírus Guaroa (GUAV), vírus Maguari (MAGV), vírus Tacaiuma (TCMV), vírus Caraparu (CARV), vírus Catu (CATV), vírus Timbó (TIMV) e vírus Belém (BLMV); e um Phlebovirus também da família Bunyaviridae - vírus Icoaraci (ICOV).

A análise descritiva foi realizada por meio de cálculo das frequências relativa e absoluta. Os resultados dos primatas soropositivos de acordo com os arbovírus testados foram calculados por frequência (\%), com o respectivo intervalo de confiança de 95\% (IC 95\%). A comparação das frequências entre espécie animal, procedência (CETAS), idade, sexo e proximidade dos recintos de manutenção dos animais de áreas de mata, foi feita por meio do teste Qui-Quadrado com auxílio do programa EpiInfo 6.0 (CDC Atlanta).

A pesquisa foi autorizada pelo ICMBio, pelo Sistema de Autorização e Informação em Biodiversidade (SISBIO), mediante a Autorização para Atividades com Finalidade Científica № 19927 e pelo comitê de Ética em Experimentação Animal (CEUA) da Universidade Federal Rural de Pernambuco (registro no 022/2012).

\section{RESULTADOS}

Não foram detectados anticorpos para os 19 arbovírus pesquisados nas 31 amostras de soros analisadas de macacos-prego-galego de vida livre do estado da Paraíba.

Das 100 amostras de soros de macacos-prego em cativeiro analisadas, em 46 (46\%) foram detectados anticorpos para nove arbovírus diferentes (9/19), foram eles: EEEV , WEEV, MAYV, MUCV, YFV, ILHV, SLEV, ROCV e para OROV. Os resultados da frequência de anticorpos inibidores da hemaglutinação para os nove arbovírus e os respectivos títulos estão apresentados no Quadro 1.

Dentre as 46 amostras positivas foram observadas reações monotípicas em 15 amostras (32,6\%), sendo quatro para ILHV, seis para MAYV, uma para SLEV, duas para ROCV, uma para OROV e uma para MUCV (Quadro 2).

Quadro 1. Distribuição da frequência de anticorpos inibidores da hemaglutinação para arbovírus em macacos-prego (Cebus libidinosus) em cativeiro, do nordeste do Brasil, 2008-2010

\begin{tabular}{lcccccccc}
\hline \multicolumn{2}{l}{ Vírus } & Positivas $(\mathrm{N})$ & \multicolumn{7}{c}{ Títulos (IH) } \\
\cline { 3 - 9 } & & $1: 20$ & $1: 40$ & $1: 80$ & $1: 160$ & $1: 320$ & $1: 640$ & $1: 1280$ \\
\hline EEEV & 15 & 4 & 4 & 3 & 4 & - & - & - \\
WEEV & 9 & 2 & 4 & 3 & - & - & - & - \\
MAYV & 29 & 1 & - & 6 & 2 & 6 & 6 & 8 \\
MUCV & 9 & 7 & - & 1 & 1 & - & - & - \\
YFV & 2 & 2 & - & - & - & - & - & - \\
ILHV & 26 & 19 & 6 & 1 & - & - & - & - \\
SLEV & 19 & 2 & 13 & 4 & - & - & - & - \\
ROCV & 12 & 3 & 4 & 4 & 1 & - & - & - \\
OROV & 28 & 15 & - & 7 & 4 & 2 & - & -
\end{tabular}

$\overline{\mathrm{N}}=$ número de amostras; $\mathrm{IH}$ = inibição da hemaglutinação; EEEV= vírus da encefalite equina leste; WEEV = vírus da encefalite equina Oeste; MAYV = vírus Mayaro; MUCV= vírus Mucambo; YFV = vírus da febre amarela; SLEV = vírus da encefalite São Luis; ILHV = vírus Ilhéus; ROCV = vírus Rocio; OROV = vírus Oropouche. 
Quadro 2. Título de anticorpos de acordo com o tipo de arbovírus detectado pelo teste de inibição da hemaglutinação em soros de macacos-prego (Cebus libidinosus) de cativeiro do Nordeste do Brasil, 2008-2010

\begin{tabular}{|c|c|c|c|c|c|c|c|c|c|c|}
\hline \multirow{2}{*}{$\begin{array}{l}\text { Registro } \\
\text { amostra }\end{array}$} & \multirow[t]{2}{*}{ Estado } & \multicolumn{3}{|c|}{ Alphavirus } & \multicolumn{3}{|c|}{ Flavivirus } & \multicolumn{3}{|c|}{ Bunyavirus } \\
\hline & & EEEV & WEEV & MAYV & MUCV & YFV & ILHV & SLEV & ROCV & OROV \\
\hline $12 \mathrm{AL}$ & $\mathrm{AL}$ & $1: 40$ & $1: 20$ & $1: 640$ & 0 & 0 & $1: 20$ & $1: 40$ & 0 & $1: 80$ \\
\hline $06 \mathrm{CP}^{*}$ & RN & 0 & 0 & 0 & 0 & 0 & $1: 20$ & 0 & 0 & 0 \\
\hline $08 \mathrm{CP}$ & PE & $1: 160$ & $1: 80$ & $1: \geq 1280$ & $1: 160$ & $1: 20$ & $1: 40$ & 1:80 & $1: 20$ & $1: 160$ \\
\hline $27 \mathrm{CP}$ & PB & 0 & 0 & 1:160 & 0 & 0 & 0 & $1: 40$ & 0 & 0 \\
\hline $29 \mathrm{CP}$ & PE & 0 & 0 & 0 & 0 & 0 & $1: 80$ & $1: 40$ & $1: 80$ & $1: 80$ \\
\hline $30 \mathrm{CP}$ & PB & $1: 80$ & 1:80 & $1: \geq 1280$ & $1: 20$ & $1: 20$ & $1: 40$ & 1:80 & $1: 20$ & $1: 160$ \\
\hline $31 \mathrm{CP}$ & PB & 0 & 0 & 0 & 0 & 0 & $1: 20$ & $1: 20$ & 0 & $1: 20$ \\
\hline P 124 & PE & 0 & 0 & 0 & 0 & 0 & $1: 20$ & $1: 40$ & 0 & 0 \\
\hline P 131 & PE & $1: 80$ & $1: 80$ & $1: \geq 1280$ & $1: 20$ & 0 & $1: 20$ & $1: 40$ & 0 & $1: 160$ \\
\hline P 135 & $\mathrm{PE}$ & 0 & 0 & 1:320 & 0 & 0 & $1: 20$ & $1: 20$ & 0 & $1: 20$ \\
\hline P $136^{*}$ & PE & 0 & 0 & $1: 320$ & 0 & 0 & 0 & 0 & 0 & 0 \\
\hline P 139* & PB & 0 & 0 & 0 & 0 & 0 & 0 & $1: 40$ & 0 & 0 \\
\hline P 141 & PB & $1: 160$ & 0 & $1: 640$ & $1: 20$ & 0 & 0 & $1: 40$ & 0 & $1: 20$ \\
\hline P 198 & PB & 0 & 0 & $1: 20$ & 0 & 0 & 0 & 0 & 0 & $1: 20$ \\
\hline P 200 & PB & 0 & 0 & $1: 640$ & 0 & 0 & 0 & 0 & 0 & $1: 80$ \\
\hline P 201* & PB & 0 & 0 & $1: 160$ & 0 & 0 & 0 & 0 & 0 & 0 \\
\hline Р 202* & PB & 0 & 0 & 0 & 0 & 0 & 0 & 0 & $1: 40$ & 0 \\
\hline P 208* & PB & 0 & 0 & $1: 80$ & 0 & 0 & 0 & 0 & 0 & 0 \\
\hline P 210 & PB & $1: 20$ & 0 & $1: \geq 1280$ & 0 & 0 & 0 & 0 & 0 & $1: 20$ \\
\hline P 213 & PB & $1: 160$ & 0 & $1: \geq 1280$ & $1: 20$ & 0 & $1: 40$ & $1: 40$ & $1: 160$ & $1: 320$ \\
\hline P 254 & $\mathrm{~PB}$ & 0 & 0 & $1: 80$ & 0 & 0 & $1: 20$ & 0 & 0 & 0 \\
\hline Р 258* & PB & 0 & 0 & 0 & 0 & 0 & $1: 40$ & 0 & 0 & 0 \\
\hline Р 262* & PB & 0 & 0 & 0 & 0 & 0 & 0 & 0 & 0 & $1: 80$ \\
\hline Р 266 & PB & 0 & 0 & 0 & 0 & 0 & $1: 20$ & 0 & 0 & $1: 20$ \\
\hline P 276 & PB & $1: 160$ & $1: 40$ & $1: \geq 1280$ & $1: 20$ & 0 & $1: 20$ & $1: 40$ & $1: 80$ & $1: 320$ \\
\hline Р 328 & $\mathrm{RN}$ & 0 & 0 & 1:80 & 0 & 0 & $1: 20$ & 0 & 0 & $1: 20$ \\
\hline P 338 & RN & $1: 80$ & $1: 40$ & $1: \geq 1280$ & $1: 20$ & 0 & $1: 20$ & 0 & 0 & $1: 160$ \\
\hline Р $349^{*}$ & RN & 0 & 0 & 0 & 0 & 0 & $1: 20$ & 0 & 0 & 0 \\
\hline P 350 & RN & $1: 20$ & $1: 20$ & $1: 640$ & 0 & 0 & $1: 20$ & $1: 40$ & 0 & $1: 20$ \\
\hline P 352* & RN & 0 & 0 & $1: 80$ & 0 & 0 & 0 & 0 & 0 & 0 \\
\hline Р 357 & RN & $1: 20$ & 0 & $1: 640$ & 0 & 0 & 0 & 0 & 0 & $1: 20$ \\
\hline Р 364 & RN & $1: 40$ & $1: 40$ & $1: \geq 1280$ & $1: 20$ & 0 & $1: 20$ & 1:80 & 0 & $1: 80$ \\
\hline Р 368* & $\mathrm{RN}$ & 0 & 0 & $1: 80$ & 0 & 0 & 0 & 0 & 0 & 0 \\
\hline P 379 & PB & $1: 40$ & $1: 40$ & $1: 320$ & 0 & 0 & $1: 40$ & $1: 40$ & $1: 20$ & $1: 20$ \\
\hline P 384 & PI & 0 & 0 & $1: 320$ & 0 & 0 & $1: 20$ & 0 & 1:80 & $1: 20$ \\
\hline P 385 & PI & 0 & 0 & $1: 80$ & 0 & 0 & 0 & 0 & 0 & $1: 20$ \\
\hline P 388 & PI & 0 & 0 & 0 & 0 & 0 & $1: 20$ & $1: 40$ & $1: 40$ & 0 \\
\hline P 389* & PI & 0 & 0 & 0 & 0 & 0 & 0 & 0 & $1: 40$ & 0 \\
\hline Р 390 & PI & 0 & 0 & 0 & 0 & 0 & 0 & 0 & $1: 40$ & $1: 20$ \\
\hline P 398* & PI & 0 & 0 & $1: 320$ & 0 & 0 & 0 & 0 & 0 & 0 \\
\hline P 402* & PI & 0 & 0 & 0 & 0 & 0 & $1: 20$ & 0 & 0 & 0 \\
\hline P 403* & PI & 0 & 0 & 0 & $1: 80$ & 0 & 0 & 0 & 0 & 0 \\
\hline P 406 & PI & $1: 40$ & 0 & $1: 640$ & 0 & 0 & 0 & 0 & 0 & $1: 80$ \\
\hline P 407 & PI & $1: 20$ & 0 & $1: 320$ & 0 & 0 & $1: 20$ & 0 & 0 & $1: 80$ \\
\hline P 408 & PI & 0 & 0 & 0 & 0 & 0 & $1: 20$ & $1: 40$ & $1: 80$ & $1: 20$ \\
\hline P 409 & PI & 0 & 0 & 0 & 0 & 0 & $1: 40$ & $1: 80$ & 0 & $1: 20$ \\
\hline Total por & bovírus & 15 & 9 & 28 & 9 & 2 & 26 & 19 & 12 & 26 \\
\hline Total por & upo & & & 61 & & & & 68 & & 26 \\
\hline
\end{tabular}

$\overline{\mathrm{EEEV}=}$ vírus da encefalite equina leste; $\mathrm{WEEV}=$ vírus da encefalite equina oeste; $\mathrm{MAYV}$ = vírus Mayaro; MUCV = vírus Mucambo; YFV = vírus da febre amarela; ILHV = vírus Ilhéus; SLEV = írus da encefalite São Luís; ROCV = vírus Rocio; OROV = vírus Oropouche. *Reação monotípica.

No total houve 17 reações heterotípicas, para dois ou mais vírus, do gênero Flavivirus, com títulos de anticorpos variando de 1:20 a 1:160. Já para o gênero Alphavirus houve 15 reações heterotípicas com títulos variando de 1:20 a 1:1280. No Quadro 2 estão discriminados os títulos de anticorpos inibidores da hemaglutinação para todas as amostras positivas.

Não houve diferença estatisticamente significativa entre os macacos-prego positivos para arbovírus segundo sexo $(\mathrm{p}=0,37)$, idade $(\mathrm{p}=0,64)$, proximidade da mata $(\mathrm{p}=0,73)$ e procedência $(\mathrm{p}=0,62)$ (Quadro 3).

\section{DISCUSSÃO}

Este trabalho representa o primeiro estudo que investigou a presença de anticorpos para arbovírus em macacos-prego-galego (Cebus flavius) de vida livre e em macacos-prego (Cebus libidinosus) de cativeiro pertencentes aos CETAS dos estados de Alagoas, Paraíba, Pernambuco, Piauí e Rio Grande do Norte.

A presença de anticorpos para 47,4\% (9/19) dos arbovírus investigados em primatas de cativeiro, apesar da possibilidade de reação cruzada no teste de $\mathrm{IH}$, pode evi- 


\section{Quadro 3. Ocorrência de anticorpos para arbovírus em macacos-prego (Cebus libidinosus) em cativeiro do nordeste do Brasil, segundo sexo, idade, proximidade da mata e procedência, 2008-2010}

\begin{tabular}{lcccc}
\hline \multicolumn{5}{c}{ Teste de inibição da hemaglutinação } \\
\hline & $\mathrm{N}$ & Positivo (\%) & IC 95\% & Valor de p \\
\hline Sexo & & & & 0,37 \\
$\quad$ Macho & 55 & $28(50,9)$ & {$[37,07-64,64]$} & \\
$\quad$ Fêmea & 45 & $18(40)$ & {$[25,69-55,66]$} & \multirow{2}{*}{0,64} \\
Faixa Etária & & & & \\
$\quad$ Filhote & 1 & $0(0)$ & {$[0,00-97,50]$} & \\
$\quad$ Juvenil & 19 & $9(47,4)$ & {$[24,44-71,13]$} & \\
$\quad$ Adulto & 80 & $37(46,2)$ & {$[35,02-57,75]$} & \multirow{2}{*}{0,73} \\
Proximidade da Mata & & & & \\
$\quad$ Sim & 58 & $28(48,2)$ & {$[34,95-61,78]$} & \\
$\quad$ Não & 42 & $18(42,8)$ & {$[27,72-59,03]$} & \\
Procedência & & & & 0,62 \\
$\quad$ CETAS Maceió & 5 & $1(20)$ & {$[0,50-71,64]$} & \\
$\quad$ CETAS Natal & 16 & $10(62,5)$ & {$[29,87-80,24]$} & \\
$\quad$ CETAS Recife & 16 & $5(31,2)$ & {$[15,19-64,56]$} & \\
$\quad$ CETAS Cabedelo & 37 & $17(45,9)$ & {$[31,92-65,60]$} & \\
$\quad$ CETAS Teresina & 26 & $13(50)$ & {$[26,58-66,62]$} & \\
Total & 100 & $46(46)$ & {$[35,98-56,25]$} & \\
\hline
\end{tabular}

N = Número de animais; CETAS = Centro de Triagem de Animais Silvestres.

denciar a circulação destes vírus nas áreas de manutenção dos animais. Entretanto, a ocorrência de 15 reações monotípicas para os ILHV $(n=4)$, MAYV ( $n=6)$, SLEV ( $n=1)$, ROCV (n=2), OROV (n=1) e MUCV (n=1) evidencia a importância epidemiológica do estudo, pois demonstra a existência do contato dos primatas com pelo menos seis diferentes tipos de arbovírus. Outras pesquisas já foram realizadas com primatas neotropicais para MAYV (De Thoisy et al. 2001, Araújo 2011, Batista et al. 2012), OROV (Nunes et al. 2005, Batista et al. 2012) e ILHV (Pereira et al. 2001).

Com relação à origem dos macacos, verificou-se que houve diferença na ocorrência de anticorpos para arbovírus entre os animais mantidos em cativeiro (46/100) e os de vida livre (0/31), possivelmente em virtude de estando em cativeiro sejam mais facilmente picados por mosquitos vetores. Já a ocorrência de anticorpos para arbovírus foi semelhante nos dois sexos, provavelmente, porque não houve diferença quanto ao local de ocupação e o grau de exposição foi similar, em consequência dos locais do cativeiro (Quadro 3). Ressalta-se que os animais com anticorpos para algum arbovírus estavam aparentemente hígidos e não houve diferença estatisticamente significativa para as variáveis sexo, idade, proximidade da mata e procedência.

Com relação às 17 reações heterotípicas observadas, para dois ou mais vírus dos gêneros Flavivirus e Alphavirus, respectivamente, os títulos de anticorpos de 1:80 a 1:1280 são considerados elevados e sugerem a circulação de alguns desses vírus na região onde os animais habitam. Causey et al. (1961) utilizaram sete macacos-prego sentinelas da espécie Cebus apella e, em várias ocasiões, identificaram infecção por dois arbovírus diferentes no mesmo macaco, constatando aumento no título de anticorpos neutralizantes. Nesta mesma pesquisa, o WEEV foi isolado de um destes macaco sentinela próximo à cidade de Belém/PA.

Considerando o diagnóstico, a reatividade cruzada entre flavivírus pode ser claramente demonstrada em testes de IH, contudo é um método que permite testar simultaneamente um grande número de amostras ante os diferentes arbovírus, o que não é viável com o teste de neutralização, mais específico. Consequentemente, sua aplicação fornece informações importantes sobre a resposta imunológica de uma determinada população contra os arbovírus (Rodrigues 2010).

A presença de anticorpos inibidores da hemaglutinação em alguns macacos-prego do presente estudo mantidos em cativeiro próximo à mata levou ao questionamento quanto ao modo de contato com os vírus por estes primatas. Considerando como possibilidade que este contato tenha ocorrido após a chegada dos animais nestes cativeiros, a transmissão pelo maruim (Culicoides paraenses) seria uma das hipóteses, uma vez que este vetor já foi descrito em mamíferos naturalmente infectados (Travassos da Rosa et al. 1996), inclusive no homem (Azevedo et al. 2007). Outra hipótese seria a transmissão por vetores que, eventualmente, poderiam ter acesso aos animais nas gaiolas, tendo como reservatórios aves naturalmente infectadas, habitando matas próximas aos cativeiros.

Em pesquisa realizada para levantamento entomológico, no Parque Estadual das Dunas, situado em Natal (RN), vizinho ao CETAS, no período de 2004 a 2006, foi constatada a existência de mosquitos transmissores de arbovírus, das espécies Aedes aegypti, Aedes albopictus e Haemagogus leucocelanus (Medeiros 2008). Considerando as arboviroses sob o aspecto de transmissão, pode-se observar que a diversidade de vetores competentes para transmissão está ligada diretamente à sua abundância no meio ambiente e à sua característica antropofílica e de repasto sanguíneo em aves, primatas, equinos, marsupiais, roedores, morcegos e outros mamíferos silvestres ou domésticos (Araújo 2011).

Investigação conduzida por Santos et al. (2011) identificou uma epizootia em 74 equinos, causada pelo EEEV, no ano de 2009, em 16 municípios do oeste da Paraíba, com taxa de $48,6 \%$ de letalidade. No Rio de Janeiro (RJ), Moreira et al. (2000) detectaram anticorpos por meio do teste de IH para o BSQV em sagui-de-duas-cores (Saguinus bicolor) e mico-leão-preto (Leontopithecus crysopygus) mantidos em cativeiro. Já Pereira et al. (2001), examinando saguis (Callithrix jacchus e Callithrix penicillata) mantidos em cativeiro durante vários anos no Parque Nacional do Tietê em São Paulo (SP), detectaram a presença de anticorpos inibidores da hemaglutinação, monotípicos para o ILHV.

Em investigação para pesquisa de anticorpos contra diferentes arbovírus em PNH de interesse em saúde pública na região do município de Porto Rico (PR), Svoboda et al. (2006) analisaram pelo teste de IH, 133 amostras de soro de macacos-prego (Cebus cay e Cebus negritus) $e$ bugio (Alouatta caraya). Vinte e uma amostras apresentaram anticorpos para SLEV, demonstrando a circulação silenciosa deste agente nos PNH daquela região. O SLEV, não patogênico para cavalo, foi isolado a partir de alguns casos clínicos humanos e de várias espécies de aves e mosquitos (constituindo os hospedeiros selváticos habituais), de macacos, marsupiais e de uma preguiça (hospedeiros casuais cujos papéis ainda são desconhecidos) (Dégallier et al. 1986).

Em pesquisa realizada na população humana das regiões Nordeste e Norte do Brasil foi encontrado um percentual de aproximadamente $5 \%$ de anticorpos específicos para 
o SLEV, na população estudada, porém estes resultados devem ser avaliados com cautela devido às reações heterotípicas entre diferentes flavivírus, principalmente nas áreas endêmicas para dengue e nas populações imunizadas contra a febre amarela. Aliás, o SLEV pode estar circulando nessas áreas e infectando as pessoas e essas infecções serem subclínicas ou inaparentes (Vasconcelos et al. 1998).

Os resultados do presente estudo estão coerentes com a descrição de que os animais silvestres são importantes reservatórios nos ciclos epidemiológicos das diversas zoonoses existentes, considerando os PNH como animais "sentinelas naturais" para investigação de determinadas epizootias de interesse em saúde pública (Svoboda 2007, Pereira et al. 2010). Segundo Kuno \& Chang (2005), o isolamento do vírus de animais suspeitos, a demonstração de viremia e a prevalência de anticorpos relativamente elevada nos animais capturados no campo são as principais informações utilizadas na identificação de reservatórios vertebrados para as arboviroses.

Além disso, a presença de vetores e mamíferos, incluindo o homem, nas regiões estudadas, pode estar favorecendo o surgimento de arboviroses emergentes, que provavelmente, estariam participando do ciclo da transmissão, tal como referiram Vasconcelos et al. $(1992,1998)$, Travassos da Rosa et al. (1996) e Pinheiro et al. (1997) em seus estudos. Desta forma, sugere-se que nos ambientes em cativeiro que mantenham macacos-prego do gênero Cebus ou outros gêneros de primatas seja realizada a vigilância entomológica e a pesquisa de reservatórios para arbovírus nos respectivos locais.

Esses resultados sinalizam que há necessidade de ênfase regional à vigilância epidemiológica das arboviroses por meio de medidas para realização dos exames de laboratório que permitam o diagnóstico etiológico.

Agradecimentos.- Ao ICMBio pelo apoio financeiro, logístico e de recursos humanos; aos CETAS, nos estados de Alagoas, Pernambuco, Paraíba, Rio Grande do Norte e Piauí, pertencentes ao IBAMA pelo apoio logístico e de recursos humanos; ao Laboratório de Sorologia do Departamento de Arbovirologia e Febres Hemorrágicas do Instituto Evandro Chagas (IEC) na cidade de Ananindeua, estado do Pará, pela realização dos exames.

\section{REFERÊNCIAS}

Araújo F.A.A. 2011. Inquérito sorológico em equídeos e aves silvestres para detecção de anticorpos anti-arbovírus de importância em saúde pública no Brasil. Tese de Doutorado, Universidade Federal de Goiás, Goiás, G0. 149p.

Azevedo R.S.S., Martins L.C., Rodrigues S.G., Travassos da Rosa J.F.S. \& Vasconcelos P.F.C. 2007. Arboviroses, p.533-551. In: Farhat C.K., Carvalho L.H.F.R. \& Succi R.C.M. (Eds), Infectologia Pediátrica. $3^{\mathrm{a}}$ ed. Atheneu, São Paulo.

Batista W.C. 2007. Mapeamento das arboviroses do Estado de Rondônia. Tese de Doutorado, Universidade Federal do Amazonas, Amazonas, AM. $110 \mathrm{p}$.

Beaty B.J., Calisher C.H. \& Shope R.E. 1986. Arboviruses, p.797-855. In: Schmidt N.J. \& Emmons R. W. (Eds), Diagnostic procedures for viral rickettsial and chlamydial infections. American Public Health Association, Washington, DC.

Catão-Dias J.L. 2003. Doença e seus impactos sobre a biodiversidade. Ciência e Cultura 55:32-34.

Causey O.R., Causey C.E., Maroja O.M. \& Macedo D.G. 1961. The isolation of arthropod-borne viruses, including members of two hitherto unde- scribed serological groups, in the Amazon region of Brazil. Am. J. Trop. Med. Hyg. 10:227-249.

Clarke D.H. \& Casals J. 1958. Techniques for hemaglutination and hemagglutination inhibition. With arthropod-borne viruses. Am. J. Trop. Med. Hyg. 7:561-573.

Contigiani M.S., Fernández C., Spinsanti L.I. \& Díaz G.E. 2000. Prevalência de anticuerpos para flavivirus en el primate Alouattta caraya autóctono de la Argentina. Medicina, Buenos Aires 60:348-350.

Cruz A.C.R. \& Vasconcelos P.F.C. 2008. Arbovírus no Brasil. Instituto Evandro Chagas, Seção de Arbovirologia e Febre Hemorrágica. Biológico, São Paulo, 70:45-46.

Dabanch J.P. 2003. Zoonosis. Rev. Chil. Infectol. 20:S47-S51.

De Thoisy B., Vogel I., Reynes J.M., Pouliquen J.F., Carme B., Kazanji M. \& Vié J.C. 2001. Health evaluation of translocated free-ranging primates in French Guiana. Am. J. Prim. 54:1-16.

Degallier N., Hervé J.P., Travassos da Rosa A.P.A., Vasconcelos P.F.C., Travassos da Rosa J.F.S. \& Sá Filho G.C. 1986. Ecologia dos arbovírus na Amazônia: pesquisas atuais e perspectiva. Revta Fundação SESP 31:127-130.

Diniz L.S.M. 1997. Primatas em cativeiro: manejo e problemas veterinários - enfoque para espécies neotropicais. Ícone, São Paulo. 196p.

Fiennes R.N., Carrington R. \& Mattews L.H. 1967. Zoonosis of primates. The epidemiology and ecology of simian diseases in relation to man. Cornell University Press, Ithaca. 190p.

Kuno G. \& Chang G.J.J. 2005. Biological transmission of arboviruses: reexamination of and new insights into components, mechanisms, and unique traits as well as their evolutionary trends. Clin. Microbiol. Rev. 18:608-637.

Medeiros A.S. 2008. Dípteros (Culicidae) transmissores de arbovírus em área de proteção ambiental urbana (Parque das Dunas Natal-RN) 20042006. Dissertação de Mestrado, Universidade Federal do Rio Grande do Norte, Natal, RN. 101p.

Moreira G.V., Peixoto C.M.S., Ziccardi M., Oliveira R.L., Castro M.G., Dionísio D.F. \& Pissinatti A. 2000. Prevalência de Trypanosoma cruzi, Trypanosoma minasense e de anticorpos contra arbovírus em primatas não humanos (Callithrichidae) em cativeiro. Rev. Bras. Med. Vet., 22: 252-254.

Nunes M.R.T., Martins L.C., Rodrigues S.G., Chiang J.O., Azevedo R.S.S., Travassos Da Rosa A.P.A. \& Vasconcelos P.F.C. 2005. Oropouche vírus isolation, Southeast Brazil. Emerg Infect Dis 11:1610-1613.

Pereira L.E., Suzuki A., Coimbra T.L.M., Souza R.P. \& Chamelet E.L.B. 2001. Arbovirus Ilhéus em aves silvestres (Sporophila caerulescens e Molothrus bonariensis). Revta Saúde Pública 35:119-123.

Pereira W.L.A., Galo K.R., Marruaz K.S.M.S., Soares M.C.P.S. \& Alves M.M.A. 2010. Ocorrência de hepatites virais, helmintíases e protozoonoses em primatas neotropicais procedentes de criação domiciliar: afecções de transmissão fecal-oral com potencial zoonótico. Revta Pan-Amazônia Saúde 1:57-60.

Pinheiro F.P., Travassos da Rosa A.P.A. \& Vasconcelos P.F.C. 1997. Febre por Oropouche, p.285-298. In: Leão R.N.Q. (Ed.), Doenças infecciosas e parasitárias: enfoque amazônico, CEJUP, Belém, PA.

Reis N.R., Peracchi A.L. \& Andrade F.R. 2008. Primatas brasileiros. Technical Books, Londrina, PR. 260p.

Rodrigues S.G., Oliva O.P., Araujo F.A.A., Martins L.C., Chiang J.O., Henriques D.F., Silva E.V.P., Rodrigues D.S.G., Prazeres A.S.C., Tavares-Neto J. \& Vasconcelos P.F.C. 2010. Epidemiologia do vírus da Encefalite de Saint Louis na Amazônia brasileira e no Estado do Mato Grosso do Sul, Brasil: elevada prevalência de anticorpos em equinos. Revta Pan-Amazônica Saúde 1:81-86.

Santos A.L., Romano A.P.M., Elkhoury A.N.S.M. \& Araujo F.A.A. 2011. Epizootias em equinos por Encefalite Equina do Leste e inquérito sorológico em equinos para detecção de anticorpos "anti-Encefalite Equina do Leste" - Paraíba/2009. [Poster] Anais XLVII Congresso da Sociedade Brasileira de Medicina Tropical 2010, Natal, RN.

Shope R.E. 1963. The use of a microhemagglutination inhibition test to follow antibody response after arthropod borne virus infection in a community of forest animals. Appl. Microbiol. 11:167-171. 
Svoboda W.K. 2007. Vigilância de epizootias em primatas não humanos como instrumento de monitoramento de arboviroses e outras viroses de interesse em saúde pública. Tese Doutorado, Universidade Estadual de Londrina, Londrina, PR. 135p.

Svoboda W.K., Martins L.C., Chiang J.O., Médici K.C., Maron A., Malanski L.S., Shiozawa M.M., Hilts C.L.S., Spohr K.A.H., Vasconcelos P.F.C. \& Navarro I.T. 2006. Investigação epidemiológica de arbovírus. In: Anais do XLII Congresso da Sociedade Brasileira de Medicina Tropical, Teresina, PI 673p.

Travassos da Rosa A.P.A., Rodrigues S.G., Nunes M.R.T., Magalhães M.T.F., Travassos da Rosa J.F.S. \& Vasconcelos P.F.C. 1996. Epidemia de febre do Oropouche em Serra Pelada, Município de Curionópolis, Pará. Revta Soc. Bras. Med. Tropical 29:537-541.

Valença-Montenegro M.M. 2011. Ecologia de Cebus flavius (Schreber, 1774) em remanescentes de Mata Atlântica no estado da Paraíba. Tese de Doutorado, Universidade de São Paulo, Piracicaba, SP, 131p.

Valença-Montenegro M.M., Silva T.C.F., Lucas J.L.B., Wagner P.G.C., Ferreira J.G., Ferreira D.R.A., Jerusalinsky L., Martins A.B., Senna M.B. \& Laroque
P.0. 2009a. Morfometria de Cebus libidinosus spix, 1823 (Primates, Cebidae). In: Anais XIII Congresso Brasileiro de Primatologia, Blumenau, SC. CD-ROM. (Resumo)

Valença-Montenegro M.M., Silva T.C.F., Lucas J.L.B., Wagner P.G.C., Ferreira J.G., Ferreira D.R.A., Jerusalinsky L., Martins A.B., Senna M.B. \& Laroque P.O. 2009b. Análise morfométrica das espécies ameaçadas de macacos-prego (Cebus Erxleben, 1777) do nordeste brasileiro. In: Anais XIII Congresso Brasileiro de Primatologia, Blumenau, SC. CD-ROM. (Resumo)

Vasconcelos P.F.C., Travassos da Rosa A.P.A., Dégallier N., Travassos Da Rosa J.F.S. \& Pinheiro F.P. 1992. Clinical and ecoepidemiological situation of human arboviruses in Brazilian Amazônia. J. Braz. Assoc. Adv. Sci. 44:117-124.

Vasconcelos P.F.C., Travassos da Rosa A.P.A., Pinheiro F.P., Shope R.E., Travassos da Rosa J.F.S., Rodrigues S.G., Degallier N. \& Travassos da Rosa E.S. 1998. Arboviruses pathogenic for man in Brazil, p.72-99 In: Travassos da Rosa A.P.A., Vasconcelos P.F.C. \& Travassos da Rosa J.F.S. (Eds), An Overview of Arbovirology in Brazil and Neighbouring Countries. Instituto Evandro Chagas, Belém, PA. 